\title{
Lo impactante y lo local: criterios de noticiabilidad y fuentes de información predominantes en la producción de noticias de delito en dos canales abiertos de Córdoba
}

\author{
Laura Rosenberg \\ laura.rosenberg85@gmail.com
}

CONICET. Universidad Nacional de Avellaneda.

Juan Martín Zanotti

jmartinzanotti@gmail.com

Universidad Nacional de Córdoba. Universidad Nacional de San Luis.

Fecha de finalización: 1 de marzo de 2020

Recibido: 2 de marzo de 2020.

Aceptado: 20 de mayo de 2020.

DOI: https://doi.org/10.26422/aucom.2020.0901.ros

\begin{abstract}
Resumen
Los medios de comunicación son uno de los actores protagónicos en dar forma a las maneras de vincularnos con la temática del delito. Entre ellos, la televisión mantiene una vigencia central que la coloca como principal productora y distribuidora de este tipo de noticias. Desde un enfoque cualitativo, a partir de la revisión de antecedentes sobre la temática y el procesamiento de entrevistas realizadas en dos de los tres canales abiertos de la provincia de Córdoba (Canal 10, de la Universidad Nacional de Córdoba, y Canal 12, propiedad del Grupo Clarín), el artículo analiza aspectos relacionados con contenidos de delito e inseguridad y los modos de producción de dicha información. Específicamente, se ocupa de los criterios a los que los periodistas recurren para identificar la noticiabilidad de los acontecimientos delictivos y las fuentes que priorizan en sus coberturas. Para ello, se plantea una perspectiva comparativa de ambas señales, donde los eventos locales marcan la pauta informativa, algo que distingue particularmente a los canales cordobeses respecto a otros del interior con cabecera en Buenos Aires. La indagación muestra similitudes y diferencias en el tratamiento de las noticias sobre delito en dos medios con estructuras de propiedad también disímiles.
\end{abstract}

Palabras clave: televisión, noticias de delito, rutinas periodísticas, noticiabilidad, fuentes de información. 
Impact and local relevance: criterias for newsworthiness and prioritized sources of information in crime news reporting in two free-to-air television channels in Cordoba

\begin{abstract}
Communication media are key players in shaping how we relate to the topic of crime. Among them, television stands center stage, being the main producer and distributor of news on this theme. Our article adopts a qualitative approach, reviewing previous work on the subject as well as interviews carried out at two of the three free-to-air channels available in the province of Cordoba (Channel 10, from the Universidad Nacional de Córdoba, and Channel 12, owned by Grupo Clarín). In doing so, it analyzes crime and public security contents and the modes of production behind them. Specifically, this article focuses on the criteria employed by journalists when identifying the newsworthiness of criminal incidents and the sources they prioritize in their reporting. To this end, it adopts a comparative view of both free-to-air channels, in which local events guide everyday coverage, something that distinguishes these Cordoba-based channels from other provincial channels headquartered in Buenos Aires. Our review shows similarities and differences in the treatment of crime stories in the surveyed Cordoba-based channels, which also have dissimilar ownership structures.
\end{abstract}

Keywords: television, crime news, journalistic routines, newsworthiness, sources of information

O chocante e o local: critérios de noticiabilidade e fontes de informação para a produção de notícias sobre crimes em dois canais abertos de Córdoba

\title{
Resumo
}

A mídia é um dos principais atores na definição das formas de vinculação com a temática do crime. Entre eles, a televisão mantém uma validade central que a coloca como principal produtora e distribuidora deste tipo de notícia. De una abordagem qualitativa, a partir da revisão de antecedentes sobre a temática e o processamento de entrevistas realizadas em dois dos três canais abertos da província de Córdoba (Canal 10 -da Universidade Nacional de Córdoba- e Canal 12 -propriedade do Grupo Clarín-), o artigo analisa aspectos relacionados ao conteúdo sobre crime e insegurança, e os modos de produção de tais informações. Especificamente, trata dos critérios aos quais os jornalistas se voltam para identificar a notoriedade de eventos criminais e as fontes que priorizam sua cobertura. Para isso, é proposta uma perspectiva comparativa dos dois canais, onde eventos locais definem a diretriz informativa, um aspecto que distingue aos canais de Córdoba em relação a outros das províncias argentinas com centro em Buenos Aires. O estudo mostra que existem semelhanças e diferenças no tratamento de notícias criminais em dois meios de comunicação com estruturas proprietárias, também diferentes.

Palavras chave: televisão, notícias sobre crimes, rotinas jornalísticas, fontes de informação, noticiário.

\section{Introducción}

El presente trabajo se apoya en los avances de una investigación financiada por la Defensoría del Público de Servicios de Comunicación Audiovisual, el CONICET y la Agencia Nacional de Promoción Científica y Tecnológica, que se ocupó del circuito 
productivo de las noticias de delito en cuatro provincias del país. ${ }^{1}$ Se trata de una indagación que reunió enfoques diferentes para caracterizar en forma integral la estructura de los medios, clasificar los contenidos informativos y reflexionar sobre prácticas periodísticas y de recepción de las noticias.

El proyecto adoptó una definición amplia de noticias de delito, que abarcó tanto las noticias de inseguridad y otras habitualmente enmarcadas bajo el género de las noticias policiales, como aquellas relacionadas a delitos en el ámbito público y privado cuya cobertura trasciende la sección policial, como sucede con casos resonantes de corrupción y delitos ambientales, entre otras cuestiones. No obstante, en consonancia con otras investigaciones locales sobre el tratamiento periodístico del delito (Calzado, Lio y Gómez, 2019; Focas y Kessler, 2015; Lorenc Valcarce, 2005), en las páginas que siguen advertimos que la problematización que los medios informativos elaboran sobre la cuestión se centra en la inseguridad, relegando el interés sobre otros delitos a un segundo plano o bien a otras secciones del medio centradas en temas políticos y judiciales.

De lo trabajado, se hace hincapié aquí en la línea de indagación sobre rutinas productivas de las noticias desde un enfoque metodológico cualitativo, con el objetivo de conocer los factores que intervienen en la elaboración noticiosa de los acontecimientos delictivos, como los criterios de selección y la jerarquización de las fuentes de información. Para este propósito, se realizó un análisis temático de diez entrevistas semiestructuradas realizadas entre diciembre de 2017 y marzo de 2018 en los espacios de trabajo de dos de los tres canales abiertos de Córdoba (Canal 10 y Canal 12). ${ }^{2}$ Con miras a comprender las distintas fases del proceso de producción de las noticias sobre delito, se entrevistó a periodistas que cumplían diferentes roles en los noticieros: cronistas, productores, conductores, camarógrafos, editores y responsables de los contenidos de ambas señales. ${ }^{3}$ La guía de entrevistas estuvo estructurada en tres ejes principales, los cuales aspiraban a recabar información sobre la organización general del proceso productivo en los noticieros, sobre las diferentes etapas del tratamiento de la información

\footnotetext{
La investigación referida se inscribe en el Proyecto de Investigación Orientada (PIO 2015-2016 CONICETDefensoría del Público) y en el Proyecto de Investigación Científica y Tecnológica (MINCyT) 2015 “De la propiedad a la recepción. Estudio integral del circuito productivo de las noticias sobre delito e inseguridad en los noticieros televisivos de mayor audiencia de la Argentina". Está dirigido por Gabriel Kessler y Natalia Aruguete en el PIO, y por Martín Becerra en el PICT, y es llevado a cabo por un grupo de investigadores argentinos de distintas provincias del país.

2 La selección de dos canales abiertos de la ciudad de Córdoba responde al criterio del proyecto macro en el que se inscribe este artículo (véase nota 1), en función del cual se seleccionaron dos canales de cada ciudad para llevar a cabo el estudio del circuito productivo y la recepción de las noticias de delito. En el caso cordobés se optó por trabajar la temática desde dos canales con estructuras productivas disímiles y líneas editoriales que, a priori, resultan diferentes.

3 Se ha entrevistado a cinco periodistas de cada canal que trabajan diariamente en el proceso productivo de las noticias sobre delito. A los fines de preservar el anonimato, en los testimonios citados solo se identifica el rol que desempeña cada entrevistado/a.
} 
Laura Rosenberg, Juan Martín Zanotti

Lo impactante y lo local: criterios de noticiabilidad y fuentes de información predominantes en la producción de noticias de delito en dos canales abiertos de Córdoba

acerca de acontecimientos delictivos (selección de estos, elaboración y procesamiento, montaje y edición y puesta en el aire) y, finalmente, sobre las economías del tiempo en el trabajo cotidiano en los noticieros. La modalidad semiestructurada permitió profundizar en aspectos que resultaron relevantes para los entrevistados o distintivos de la forma de trabajo de estos noticieros de cara al análisis comparativo entre ambas señales. El énfasis en lo local y la centralidad de la fuente institucional policial son aspectos que ilustran lo mencionado y que serán desarrollados en las próximas páginas.

El corpus fue procesado y analizado mediante la confección de una grilla desagregada de indicadores que fue cruzado con datos obtenidos en otras provincias (Santa Fe, Mendoza y Buenos Aires), donde también se realizaron entrevistas. En lo que respecta al objetivo de este artículo, en el análisis se tomaron en cuenta las siguientes dimensiones, las cuales fueron problematizadas en función de los hallazgos resultantes del trabajo de campo en ambos medios: 1. recorte de temáticas y conformación de agenda sobre delito y violencia; 2. cobertura territorial de los acontecimientos; 3 . jerarquización de fuentes de información; y 4. principales dinámicas para la producción.

\section{El proceso de construcción de las noticias de delito. Herramientas de análisis}

Antes de introducir las principales categorías teóricas, cabe remarcar que la problemática de la seguridad pública asumió diferentes sentidos históricos y, por ello, existen diversas formas de abordar la cuestión securitaria (Foucault, 1999). Para este trabajo, se recupera principalmente el quiebre producido en la década de 1990 en Argentina y, en un sentido más extendido, para América Latina, donde la inseguridad emergió en un contexto de auge del neoliberalismo como un problema social y como un objeto de intervención gubernamental (Kessler, 2009).

Desde esta etapa se produjo un aumento significativo en la representación mediática del delito, que tuvo impacto en el campo de las políticas públicas. Como menciona Stanley Cohen (citado en Aruguete y Amadeo, 2012, p. 181), a la idea de inseguridad se adhirió la idea colectiva de "pánico moral", y la creciente preocupación por el delito repercutió en actitudes abiertamente punitivas. El impacto de la temática en los medios de comunicación tuvo y tiene la televisión como un protagonista central, en la medida en que el medio continúa siendo el más consumido en Argentina. ${ }^{4} \mathrm{~A}$ lo que cabe agregar que el género informativo se vuelve un lugar privilegiado en el modo de presentar los hechos que acontecen en la televisión, ya que forma hábitos de consumo de información y modos "legitimados" de comprensión de la realidad.

\footnotetext{
4 La Encuesta Nacional de Consumos Culturales (Sistema de Información Cultural de la Argentina, 2017) muestra que prácticamente todos los argentinos miran televisión y lo hacen a través del televisor como soporte principal (95\%). La novedad la introduce el dato de que más de la mitad de los televisores de los hogares son smart TV (54\%).
} 
Desde los trabajos pioneros de la sociología de la producción de las noticias se ha remarcado una de las paradojas del proceso laboral en medios informativos y, específicamente, de su producto: las noticias. Aun cuando la "materia prima" refiere a acontecimientos imprevistos -que, en muchos casos, quiebran la rutina de la vida social-, quienes trabajan sobre estos "hechos ruptura" (Rodrigo Alsina, 1993) son capaces de describir una dinámica de trabajo cotidiano, de "rutinizar lo inesperado" (Tuchman, 1983). Múltiples investigaciones desarrolladas por la sociología de la producción de las noticias -especialmente los trabajos pioneros de autores como Altheide (1984), Epstein (2000), Fishman (1988), Gans (2004), Golding y Elliot (1979), Schlesinger (1987), Tuchman (1983) y Tunstall (1978)- evidenciaron que los periodistas pueden dar cuenta de la existencia de esas rutinas en las cuales los acontecimientos imprevistos son transformados en noticias. Esta perspectiva puso en cuestión los enfoques sobre las noticias como reflejo de lo social y destacó la adopción de una perspectiva constructivista para analizar el trabajo informativo.

Para esta investigación se requirió a los entrevistados la reconstrucción de las jornadas típicas de trabajo en los medios informativos, a los fines de conocer cómo se elaboran las noticias sobre delito. Como podrá verse más adelante, esto posibilitó conocer las fuentes de información más consultadas y el modo en que la inseguridad es definida y encuadrada en los medios, jerarquizando, en ambos casos, la cuestión policial. En este sentido, la perspectiva constructivista de la noticia permitió, entre otras cuestiones, desnaturalizar la asimilación entre noticias de delito y noticias policiales; el hecho de que la mayoría de los entrevistados las presenten en forma análoga llevó a analizar el peso de la institución policial en la conformación de la agenda mediática, así como la exclusión del tratamiento de otro tipo de delitos.

\section{Antecedentes sobre los canales elegidos}

Diversos estudios han dado cuenta de la correlación que existe entre la propiedad concentrada de medios y la homogeneización de contenidos y líneas editoriales en televisión, así como de la centralización y la falta de pluralidad en las propuestas informativas (Becerra y Mastrini, 2017). Como plantea Martín Becerra (2015), concentración e interés público no pueden ser disociados del análisis de la conformación de los medios e industrias que producen y distribuyen masivamente información.

En este esquema se destacan dos grupos empresarios con presencia decisiva en Córdoba: Telefé - adquirido por VIACOM- y el Grupo Clarín, los cuales poseen dos de los tres canales abiertos ${ }^{5}$ que pueden verse en toda la provincia: Canal 8, hoy renombra-

\footnotetext{
Canal 12 (creado en 1959) fue la primera señal de aire en Córdoba. Le siguió Canal 10, con sus primeras transmisiones en 1960, y finalmente Canal 8, en 1963. Desde entonces, los tres sufrieron múltiples transformaciones institucionales, que, en el caso de los canales 8 y 12, también estuvieron vinculadas con sus composiciones accionarias.
} 
Laura Rosenberg, Juan Martín Zanotti

Lo impactante y lo local: criterios de noticiabilidad y fuentes de información predominantes en la producción de noticias de delito en dos canales abiertos de Córdoba

do como Telefé Córdoba, y Canal 12, respectivamente. La tercera señal pertenece a los Servicios de Radio y Televisión (SRT) de la Universidad Nacional de Córdoba -posee un $99 \%$ de la composición accionaria-, la cual tiene la figura legal de una sociedad anónima y se gestiona con un importante margen de autonomía. El multimedio universitario está compuesto también por la señal de radio AM Universidad, fundada en 1958, una FM y una segunda señal lanzada en el año 2011 para el sistema de Televisión Digital Abierta (TDA), que comenzó como canal de noticias (Cba24n) y, posteriormente, se convirtió en una señal extensionista de contenido estrictamente universitario (Canal U).

La predominancia de los canales pertenecientes a los grupos de medios concentrados, cuyos propietarios son empresas de la Ciudad Autónoma de Buenos Aires, genera una dependencia de los materiales producidos allí. Esta situación no se corrobora igual en todos los contenidos; estudios antecedentes dan cuenta de que en los contenidos locales predominan los segmentos informativos, los cuales son especialmente valorados por las audiencias. Dos monitoreos previos (Defensoría del Público de Servicios de Comunicación Audiovisual, 2015; Mata, Morales y Martinez Luque, 2016) ${ }^{6}$ de los tres canales abiertos de Córdoba realizados durante los años 2014 y 2015 muestran que estos priorizan en sus coberturas noticias -y volúmenes de notas- de los ámbitos geográficos más cercanos. Los datos para 2014 exponen una marcada preferencia por la producción de notas "locales", que se llevan el 61\% del total, relegando a las nacionales (14\%) y a las internacionales (11\%). En tanto, lo relevado para 2015 expone un porcentaje más elevado aún: el $64 \%$ para las que aluden al ámbito cordobés, el 18\% para las nacionales y el $8 \%$ para las internacionales.

El tratamiento prioritario de lo local, principalmente circunscrito a la capital provincial -y, de manera marginal, a las localidades del resto de Córdoba-, marca una tendencia que no siempre se comprueba cuando se construyen los temas políticos. La política escapa por momentos a esta regla, adquiriendo más presencia en las pantallas las derivaciones de los conflictos y debates de la política nacional con sede en Buenos Aires, lo que configura también un sesgo. En este punto, también hay matices entre los canales Telefé Córdoba y Canal 12, y Canal 10. De los dos primeros, es Canal 12 quien ha tensado la relación Gobierno/oposición durante las gestiones del kirchnerismo, y continuó apuntando contra los exfuncionarios de esas administraciones una vez que Cambiemos se hizo del poder.

Dicho esto, una primera comparación entre Canal 12 y Canal 10 nos lleva a advertir diferencias respecto a su estructura de propiedad y a su línea editorial. Además de lo mencionado, cabe marcar algunas exigencias y estándares esperables alrededor

Relevamientos de programas informativos de los tres canales de aire de Córdoba, en los que se analizaron seis meses alternados -febrero, abril, junio, agosto, octubre y diciembre- para los años 2014 y 2015. 
del universo de los medios públicos, planteados en trabajos que sistematizan "buenas prácticas" o plantean un papel diferencial respecto a los medios privados en dimensiones que van desde la gestión de las emisoras y la producción de contenidos hasta la participación de parte de las audiencias (Bucci, Chiaretti, y Fiorini, 2012; De Charras, 2016). A partir de estos antecedentes, se asume que podrían primar allí elementos como la pluralidad informativa, la variedad de fuentes de información o el respeto por la diversidad cultural y social. Elementos estos que aplicarían para el estudio de Canal 10, pero que, al mismo tiempo, demandarían una entrada específica que no es el objetivo de este trabajo, por lo que aquí se realiza desde lo que los informantes recuperaron en relación con la temática específica.

Ambos canales tienen una oferta de contenidos que incluye programas de entretenimiento e interés general, programas infantiles, programas de ficción de producción nacional y extranjera y programas informativos. Esta diversidad de contenidos demuestra que no se trata de canales de noticias exclusivamente; no obstante, los noticieros ocupan buena parte de las grillas de programación, tendencia que comparten con otros canales de aire locales y nacionales (Pelitti, Mársico y Casazza Herrera, 2011).

En el caso de Canal 12, un 60\% de la programación de lunes a viernes es propia del canal de cabecera (Canal 13). Mientras que la mañana es el horario que el canal priorizó para la distribución de producciones locales, las tardes comparten el contenido de Canal 13 en un $100 \%$. El canal transmite cinco ediciones diarias de noticieros, tres de los cuales son de producción local (Arriba Córdoba, Noticiero 12 y Telenoche) y dos de Canal 13 (Noticiero 13 y Síntesis).

El tiempo de programación destinada a los noticieros es análoga en Canal 10, que también cuenta con cinco ediciones diarias, de las cuales tres son de producción propia (Crónica Mediodía, Crónica Central y Crónica al Cierre) y dos corresponden a ediciones del noticiero de la Televisión Pública Argentina que se produce en la Ciudad de Buenos Aires.

En términos de audiencias, Telenoche y Noticiero 12 lideran marcadamente los informativos locales de los canales abiertos, con una distancia más que considerable sobre las ediciones de Teleocho Noticias y relegando al último lugar a las Crónicas del $10,{ }^{7}$ en una diferencia que se acrecentó en los últimos años y muestra en la actualidad una relación de 10 puntos de rating promedio contra 1.

De acuerdo con las mediciones de Kantar Ibope al 5 de mayo de 2019 -procesadas tomando cuatro semanas móviles hasta esa fecha-, las ediciones de mediodía ubican primero a Noticiero Doce con 10,7 puntos, segundo a Teleocho Noticias con 5,3 puntos y tercero a Canal 10 con 1 punto de rating (en enero de 2018 registraba dos puntos). Las ediciones centrales de la noche, por su parte, muestran el mismo orden con valores similares: 11,7 puntos de Canal 12 contra 7,6 de Telefé Córdoba, y menos de 1 punto $(0,9)$ para el canal universitario. Obtenido el 29 de julio de 2019 de http://www.eldoce.com.ar/comercial/mediakit_tv.pdf 
Laura Rosenberg, Juan Martín Zanotti

Lo impactante y lo local: criterios de noticiabilidad y fuentes de información predominantes en la producción de noticias de delito en dos canales abiertos de Córdoba

\section{Las dinámicas para producir las noticias y las economías del tiempo}

Ante la pregunta sobre cómo es un día de trabajo en el noticiero, los periodistas describieron su jornada laboral indicando horarios de llegada y salida, reuniones de producción y rutinas asociadas a sus intercambios con fuentes de información. De las narraciones se desprende, en todos los casos, una distinción respecto a los propósitos y la organización del trabajo de cada emisión del noticiero y el lugar que ocupan las noticias de delito y policiales en cada una:

Los horarios extremos te llaman a noticias policiales porque el horario de la noche es casi todo policial, dado que ya no hay noticias cotidianas. Digamos, los actos ya pasaron, todo el movimiento del día ya pasó y lo que queda es la noticia policial, es lo que salta, netamente policial, y en el horario de la mañana también (cronista de Canal 10). ${ }^{8}$

Desde la dirección del Canal 10 se explicita la decisión de asignar a cada emisión del noticiero una impronta diferente, que se adapte a una audiencia que, a lo largo de la jornada, se informa de los sucesos por diversos medios de comunicación. Con base en esta rutina de las audiencias, los canales configuran los perfiles de cada noticiero. En ambos canales, el matinal está orientado a una audiencia "que no es fija" y se centra en brindar información nueva. Al mediodía, la oferta responde a un formato "más tradicional". En el caso de Canal 10, en esta emisión fracasaron apuestas innovadoras $\mathrm{y}$ acabaron adoptando un formato similar al que ofrece la competencia, el noticiero de Canal 12, que es el que hace décadas tiene los mayores índices de audiencia. Por último, la edición central propone un tratamiento más profundo de las noticias que estuvieron desarrollándose durante el día, sobre las cuales la audiencia cuenta ya con información previa:

[En la edición] matinal, lo que tratamos de hacer es lo último de la mañana y tratamos de que sean cuatro noticieros en esas dos horas. No tenemos problema en repetir la información para el que recién se suma, agregándole datos nuevos [...] De lo más tradicional que tenemos es [el noticiero del] mediodía. De todas maneras, es lo que rinde en Córdoba. Nosotros tenemos el noticiero más visto hace años, el del canal 12 [...] [En la edición central] nosotros tenemos dos mesas de debate. Lo diagramamos de dos maneras, una cosa es la calidad de la noticia y otra es la horizontalidad. La horizontalidad tratamos de profundizarla un poco más con datos, con cosas concretas del tema del día y tratamos de darle un poco más de contenido y de opinión (director de noticias de Canal 10). ${ }^{9}$

En Canal 12 también se plantea una diferenciación entre las propuestas de los noticieros, que resulta coincidente con las de Canal 10 en su ajuste a las rutinas y características de las audiencias en cada horario:

8 Entrevista personal, realizada el 11 de diciembre de 2017, Ciudad de Córdoba.

9 Entrevista personal, realizada el 11 de diciembre de 2017, Ciudad de Córdoba. 


\begin{abstract}
Cada noticiero tiene su formato particular. Ninguno de los tres noticieros es igual. Creo que el más tradicional es el del mediodía, pero por una cuestión de los televidentes, que es gente más grande, que está en la casa. El de la mañana es una cuestión más de darle un panorama, qué va a pasar en el día, incluso a las notas se les cortan off, salen como muy fragmentadas. Al mediodía es más tradicional y a la noche la idea es hacer como otra apuesta. Nosotros, con una policial, hacemos la nota, la presentan en el piso, podemos hacer un refuerzo a lo mejor con las redes [...] A la noche se desglosa más la noticia, sobre todo si es una noticia grosa. Entonces, por ahí, se busca a un especialista (productora de Canal 12). ${ }^{10}$
\end{abstract}

Respecto a la posibilidad de presentar contenidos con mayor nivel de desarrollo, prácticamente en todos los testimonios se apuntaron dificultades vinculadas con los tiempos para el procesamiento de datos y el armado de los productos informativos, sobre todo en el caso de las noticias de "último momento": "Tenés cinco minutos para ver todo, porque hacés muchas cosas más", sintetizaba una entrevistada de Canal 10. ${ }^{11}$

Asociadas a la superposición de tareas y a las posibilidades para elaborar las notas, surgieron las opciones por crónicas o informes para cubrir los acontecimientos ligados con el delito y la inseguridad. Como enfatiza un productor de Canal 12, las diferentes clases de tratamiento de las noticias no se definen exclusivamente en relación con la importancia o ponderación de los hechos ni tampoco en función de las potenciales reacciones del público:

Se cubre con relación a los tiempos [...] Si hay un tipo muerto en una calle, es una noticia simple. Se cubre, se habla con algún policía, con algún familiar. [Si hay] un tiroteo en Nueva Córdoba, se trata de buscar al protagonista, al tipo que le robaron y demás. En el caso del informe, es un poco más amplio (productor de Canal 12). ${ }^{12}$

En las crónicas también se señalaron cambios respecto a formas tradicionales del trabajo periodístico, en la medida en que las noticias para televisión se redactan cada vez menos, lo que da cuenta de cierto cambio de esquema en el que también desaparece progresivamente la voz en off y se prioriza la narración de los protagonistas o testigos de los hechos. Como se encargaron de marcar distintos responsables de la elaboración de informes, estos contenidos se plantean como notas más complejas que pueden incorporar narraciones más completas que agregan otros actores del hecho $\mathrm{y}$, principalmente, mayores recursos en la etapa de posproducción:

Los informes especiales son notas "tuneadas" con mucha gráfica, con ritmo. Ahí somos varios los que estamos [...] Los informes son como recopilaciones más registros de todas las imágenes. Se les da otro estilo y otra forma (editor de Canal 12). ${ }^{13}$

10 Entrevista personal, realizada el 12 de diciembre de 2017, Ciudad de Córdoba

11 Entrevista personal, realizada el 11 de diciembre de 2017, Ciudad de Córdoba.

12 Entrevista personal, realizada el 13 de marzo de 2018, Ciudad de Córdoba.

13 Entrevista personal, realizada el 13 de marzo de 2018, Ciudad de Córdoba. 
Laura Rosenberg, Juan Martín Zanotti

Lo impactante y lo local: criterios de noticiabilidad y fuentes de información predominantes en la producción de noticias de delito en dos canales abiertos de Córdoba

También, en función de lo anterior, aunque no son tan frecuentes, los informes permiten otro tipo seguimiento:

Informes en lo policial es un poco más complicado, porque lo policial es inmediato la mayoría de las veces. Después lo podés ampliar, digamos, con lo social, con el entorno de lo policial, pero lo policial en sí es inmediato (productora de Canal 10). ${ }^{14}$

En relación con la "inmediatez" -una cualidad que la entrevistada le atribuye a lo policial-, el encargado de la elaboración de informes especiales de Canal 12 coincidió al plantear que este género de noticias habitualmente se presenta como "último momento" y que aportan el condimento del vivo y en directo, el cual resulta atractivo para la audiencia televisiva: "Básicamente tenés un show, algo que ya sabés que va a ocurrir en el teatro, una puesta.". ${ }^{15}$ Esta frase condensa una de las características de la televisión como un medio que ha tendido a combinar la información con el entretenimiento, donde el "vivo y en directo" resultó uno de sus aspectos más novedosos en la era predigital (Landi, 1993; Scolari, 2008). En este aspecto, una diferencia relevante entre los canales locales y los nacionales lo aporta la medición del rating en tiempo real, factor que tiende a alterar la dinámica de los noticieros en vivo de los canales de Buenos Aires, en contraste con lo que ocurre en los canales del interior del país, donde las cifras son dadas a conocer semanas posteriores a cada emisión. En Córdoba, no es posible establecer aquella correlación que advierten periodistas de los canales nacionales entre el tipo y la extensión de las coberturas del noticiero y los resultados de las mediciones realizadas "minuto a minuto": ${ }^{16}$

Nosotros no tenemos [medición del rating en tiempo real]. Es una pena, pero no lo tenemos como en Buenos Aires. A nosotros nos mide también Ibope, pero no tenemos el minuto a minuto. Al contrario, tenemos un retraso de dos semanas. Entonces, no te sirve como herramienta para ver dónde estás (director de noticias de Canal 10). ${ }^{17}$

En este sentido, la dinámica de los noticieros de los canales locales es menos sensible a cambios en función de las mediciones, como los que ocurren entre sus pares de Buenos Aires, donde tienen a mano los índices de rating en tiempo real. El mayor interés que se le atribuye a la audiencia sobre los contenidos transmitidos en vivo y en directo solo es comprobable en los canales locales en forma asincrónica.

\footnotetext{
${ }^{14}$ Entrevista personal, realizada el 11 de diciembre de 2017, Ciudad de Córdoba.

${ }^{15}$ Entrevista personal, realizada el 12 de diciembre de 2017, Ciudad de Córdoba.

${ }^{16}$ La comparación obedece a los resultados del análisis de las entrevistas realizadas a periodistas de canales locales y nacionales en el marco del proyecto al cual nos referimos anteriormente y en el que se inscriben los hallazgos del artículo.

17 Entrevista personal, realizada el 11 de diciembre de 2017, Ciudad de Córdoba.
} 
Por su parte, el factor o componente social de las noticias de delito fue señalado de manera recurrente como uno de los criterios para la continuidad de las diferentes historias construidas como casos:

\begin{abstract}
Hay una nota que viene desde hace años. Un delincuente mató a una chica que estaba comprando con su mamá. Que está acá, cruzando el puente, un barrio bastante heavy. Este chico fue a un Complejo Esperanza, que alberga a menores del delito, cumplió su condena, salió con un arma, que se la había robado a la jefatura de policía, mató a otras dos personas, cometió diez delitos más graves (productora de Canal 12). ${ }^{18}$

Hubo un tiroteo, un robo a una carnicería en un barrio humilde, de personas muy trabajadoras de Córdoba, que se llamaba Villa Libertador, allí hirieron al verdulero [...] A ese hecho se lo siguió muchos días hasta que a este chico le dieron de alta y se le vio el lado social, tomó una trascendencia muy especial (productora de Canal 10). ${ }^{19}$
\end{abstract}

Tanto los hechos que se presentan como los recursos empleados en la narración apuntan a una audiencia que empatice con las víctimas, tal como plantean Calzado, Lio y Gómez (2019):

\begin{abstract}
Es un enunciatario que se solidariza con la víctima y sus familiares, que se conmueve, sorprende, indigna y espanta junto con los presentadores del noticiero, con mayor apelación al tono emotivo en las señales privadas. En casos de homicidios, los conductores editorializan aportando dramatismo al relato, apelan a la emoción/conmoción, incluso con descripciones de imágenes (p. 234).
\end{abstract}

En la producción y distribución de estas noticias, imágenes de lo "real" se condensan con elementos de lo ficcional con miras a informar, sensibilizar y prevenir a los televidentes. Advertimos que estos componentes se emplean en la etapa de producción, pero, además, contribuyen en una etapa previa a fundamentar la propia caracterización de las noticias de este género.

Para comprender la noticiabilidad de diferentes hechos delictivos, se indagó en los criterios de selección empleados por los periodistas de noticieros de ambas señales televisivas, donde las diferencias editoriales no bifurcan en este aspecto los caminos que consolidan las noticias de delito como "noticias policiales", en las cuales los delitos contra la vida y la propiedad privada son los que priman en la agenda.

\title{
La fatalidad y la agenda local sobre delito
}

A partir de entrevistas realizadas a periodistas de Canal 12 y de Canal 10, se confirma lo referido anteriormente sobre la agenda local de sus noticieros, que en temas de delito e inseguridad muestra una tendencia acentuada sobre lo que ocurre en Córdoba. Los entrevistados refirieron que son escasas las presentaciones y coberturas

18 Entrevista personal, realizada el 12 de diciembre de 2017, Ciudad de Córdoba.

19 Entrevista personal, realizada el 11 de diciembre de 2017, Ciudad de Córdoba. 
Laura Rosenberg, Juan Martín Zanotti

Lo impactante y lo local: criterios de noticiabilidad y fuentes de información predominantes en la producción de noticias de delito en dos canales abiertos de Córdoba

de noticias de este género que tienen lugar fuera de la provincia, cuestión que marca una diferencia notable respecto a lo referido por periodistas de noticieros analizados en Santa Fe o Mendoza:

La estructura fuerte de los noticieros nuestros es más bien local. Te diría que el 95\% es local $[. .$.$] nuestra audiencia es de Córdoba capital, ese es el negocio nuestro. Pero alrede-$ dores, que está todo cerca acá, 40 o 50 kilómetros, lo hacemos y forma parte de la estructura que tenemos en ese tipo de hechos. Fuera de la provincia de Córdoba tiene que ser un hecho muy grave (director de noticias de Canal 10). ${ }^{20}$

En aquellos casos en los cuales, por la permanencia de un tema en la agenda mediática, se decide cubrir un acontecimiento ocurrido en otras provincias, se asume que la audiencia reclama una cobertura propia en el lugar de los hechos. Como aseguró una productora de Canal 12: "El cordobés es muy particular, le gusta lo que es la localía, el tema de escucharlo por los cronistas propios". ${ }^{21}$

En el caso de Canal 12, perteneciente al Grupo Clarín, un cronista destaca la necesidad de aportar una cobertura propia sobre los hechos, a pesar de que siempre pueden "recibir en limpio" lo realizado por TN o Canal 13:

Nosotros, en Canal 12, trabajamos independientemente, hacemos nuestros temas, siempre peleamos por hacer nuestras coberturas [...] Pero existe una tendencia a decir "si está Juan, ¿para qué...?”. ¿Y quién lo conoce a Juan? Aquí lo conocen a Néstor Ghino, que esté en la Patagonia con el tema de los mapuches, es nuestra cara, nuestro representante de esta sociedad [...] Y siempre la peleamos, hemos peleado algunas veces con más suerte que en otras. Y el [Canal] 13 tiene su propia impronta, que hagan su vida (cronista de Canal 12). ${ }^{22}$

No obstante, en ambas señales resulta cada vez más difícil responder a la demanda de cubrir con voz propia lo acontecido fuera de la ciudad de Córdoba, donde funcionan operativamente los canales, teniendo en cuenta los recursos económicos que requiere la tarea. De modo que el vínculo con otras señales del interior y de Buenos Aires termina primando en buena parte de las ocasiones. En varios testimonios, los casos de femicidio fueron apuntados como ejemplos paradigmáticos de hechos que ameritan coberturas en el interior provincial que no pueden efectivizarse por reducción de costos para la producción de las noticias, acorde a lo planteado por una trabajadora de Canal 12: "Hay una tendencia a achicar, digamos, la producción y toda la historia. Antes se viajaba mucho. Había un accidente, un femicidio, nosotros viajábamos. Y eso se ha reducido mucho. Hoy por hoy, recurrimos mucho a los canales del interior".

Además del énfasis en la cuestión local, se indagaron otros criterios que, según la perspectiva de los periodistas, definen la noticiabilidad de un acontecimiento delicti-

${ }^{20}$ Entrevista personal, realizada el 11 de diciembre de 2017, Ciudad de Córdoba.

21 Entrevista personal, realizada el 12 de diciembre de 2017, Ciudad de Córdoba.

${ }^{22}$ Entrevista personal, realizada el 12 de diciembre de 2017, Ciudad de Córdoba. 
vo. En primer lugar, cabe destacar que el mecanismo en función del cual las organizaciones periodísticas seleccionan temas noticiables entre una multiplicidad de sucesos que ocurren "inesperadamente" es percibido por los periodistas como un proceso natural que se desarrolla durante las rutinas de trabajo en los medios (Gans, 2004; Shoemaker y Reese, 2013; Tuchman, 1983). De modo que la posibilidad de conocer qué características deben reunir los sucesos para ser tratados en el noticiero demanda, por parte de los entrevistados, una reflexión que permite sacar a la luz aquellas reglas que tienden a darse por sentado y que, sin embargo, organizan la cotidianidad laboral. Así como apuntaron los autores de la perspectiva del newsmaking, en los testimonios que recabamos se sugiere primeramente que esa selección de los hechos noticiables es efectuada de manera "automática" y que se agiliza con la "experiencia" o con "los años", como enfatiza el siguiente testimonio de una productora del canal universitario:

Yo creo que la selección de noticias es a partir de un criterio de selección. ¿Cuándo se adquiere ese criterio? Con la experiencia. El productor se va a dar cuenta [...] de qué noticias son las más importantes del día y que van a formar parte de la agenda y van a marcar (productora de Canal 10). ${ }^{23}$

Al explicar cómo puede identificarse la relevancia de un hecho delictivo, los periodistas entrevistados de ambos canales refieren al nivel de gravedad de este, donde la muerte pareciera ser el indicador adecuado para documentar la fatalidad como criterio de noticiabilidad:

Uno ya sabe cuándo es grave. Lamentablemente, la noticia va por donde pasan las cosas más graves [...] En lo policial, muertos, sobre todo cuando hay menores. Una noticia grave es cuando hay un menor fallecido, y si no hay menores, cuando hay una persona muerta [...] Todo lo fatal es lo más importante en lo policial (productora de Canal 10). ${ }^{24}$

Si consideramos lo elaborado por Entman (1993) en torno a los encuadres of frames de las noticias, vemos que los casos más violentos o resonantes se imponen sobre otros: ${ }^{25}$

Motines, asaltos, incendios, manifestaciones, todo ese tipo de noticias [...] nosotros decimos siempre en la jerga: "levantamos los muertos de la madrugada" [...] Homicidios son la diaria, últimamente, violencia urbana. Muchísima violencia urbana (productora de Canal 10). ${ }^{26}$

Si matan a una persona de diez tiros, vamos a estar todos, vamos a estar en el hecho, vamos a buscar hasta que eso se calme. Pero hemos dejado de caminar los lugares para encontrar

${ }^{23}$ Entrevista personal, realizada el 11 de diciembre de 2017, Ciudad de Córdoba.

24 Entrevista personal, realizada el 11 de diciembre de 2017, Ciudad de Córdoba.

${ }^{25}$ Una entrevistada en Canal 12 marcaba, por ejemplo, que ya no se cubren robos comunes, pero sí se mencionan en los casos en que se registran heridos u otro tipo de incidentes similares.

${ }^{26}$ Entrevista personal, realizada el 11 de diciembre de 2017, Ciudad de Córdoba. 
Laura Rosenberg, Juan Martín Zanotti

Lo impactante y lo local: criterios de noticiabilidad y fuentes de información predominantes en la producción de noticias de delito en dos canales abiertos de Córdoba

la noticia, es como que todos juntos vamos a donde hay comida, rapiña (conductor de Canal 12). ${ }^{27}$

En el testimonio que se expone a continuación, vemos que, cuando se extrema la fatalidad del hecho, el criterio de cercanía geográfica que se expuso al comienzo de este apartado puede pasar a segundo plano:

\begin{abstract}
Si no es en Córdoba capital y está en la provincia de Córdoba, tiene que ser algo que a nosotros nos den los tiempos para tratarlo ese mismo día y donde estemos seguros de que vamos a poder llegar a ese evento [...] Tienen que ser casos importantes: un femicidio, un femicidio seguido de suicidio, alguna masacre que no se da habitualmente, tiene que ser muy resonante (productora de Canal 12). ${ }^{28}$
\end{abstract}

La centralidad que adquieren los hechos asociados a la inseguridad y a la violencia en la configuración de la agenda sobre delito en estos medios lleva a que este tipo de noticias sean identificadas como "policiales", y a que la institución policial tenga primacía en ambos canales a la hora de definir este tipo de acontecimientos.

En relación con esto y como dato relevante del canal universitario, se puede apuntar la creación de un documento colectivo - de circulación interna- al que accedimos durante el trabajo de campo titulado "Reglas de Estilo para trabajar en el informativo de Canal 10, Radio Universidad y FM Power". 29 En este material, elaborado en 2009, quedaron expresadas una serie de normas generales y recomendaciones vinculadas con temáticas como el delito, donde se consignaba, por ejemplo, que: "Siempre debe ser mencionada como presunta la culpabilidad de una persona cuando el hecho no ha sido motivo de fallo jurídico que declare su culpabilidad. En una sociedad democrática es la Justicia la que da por probado un delito". Si tomamos este documento como una guía para la práctica periodística -como se recomienda para los medios públicos-, resulta interesante esta definición institucional, en tanto podría alertar acerca de la utilización de fuentes únicas (la policial, por caso) y prevenir sobre la lectura anticipada de los hechos y la consecuente adjudicación previa de responsabilidades sin posibilidad de defensa.

$\mathrm{Al}$ respecto, en Canal 10, un entrevistado marcó una crítica a la línea editorial del medio que, en 2016, atravesó un cambio de gestión, apuntando que a partir de entonces el medio cedió autonomía respecto a aquella institución al momento de marcar el tratamiento de las noticias sobre delito e inseguridad:

\footnotetext{
27 Entrevista personal, realizada el 12 de diciembre de 2017, Ciudad de Córdoba.

28 Entrevista personal, realizada el 12 de diciembre de 2017, Ciudad de Córdoba.

29 En esta suerte de manual de funcionamiento interno, también se sugiere que los casos de violencia de género no deben plantearse como si fueran "casos o crímenes pasionales" (regla 27), algo que es oportuno subrayar debido a que esta recomendación fue formulada antes que la problemática de género consiguiera mayor instalación en el debate público y mediático en el ámbito local.
} 


\begin{abstract}
Ahora se tiene una mirada por ahí más vinculada a la institución, más tradicional, de cuestionar menos a la institución policial [...] Aquella línea editorial tendía más a cuestionar el accionar de las instituciones que representan el monopolio de la violencia del Estado. Hoy por hoy, no hay una decisión tan firme de cuestionar eso (periodista de Canal 10). ${ }^{30}$
\end{abstract}

El lugar que asumen las fuentes a la hora de definir el encuadre de las noticias ha sido debatido en la bibliografía sobre trabajo periodístico, donde se cuestiona el supuesto rol pasivo de los informantes en la elaboración de las noticias cuyos constructores serían exclusivamente los periodistas. En contraposición a ello, algunos autores han destacado el carácter negociado del proceso de construcción de las noticias a partir de la atención en el vínculo entre periodistas y sus fuentes (Berkowitz, 2009; Gans, 2004; Lemieux, 2000).

En relación con nuestro objeto de análisis, en el próximo apartado se profundizará sobre el rol activo que desempeñan las distintas fuentes de información a las cuales recurren los periodistas de ambos canales durante sus rutinas de producción de noticias de delito. Nos detendremos específicamente en el rol central que adquieren las fuentes policiales a la hora de definir el encuadre de este tipo de noticias.

\title{
La policía como fuente privilegiada
}

Lo mencionado anteriormente en relación con las maneras de encuadrar las noticias se manifiesta también en los tipos de fuentes principales, donde se destacan notablemente las fuentes institucionales y, entre ellas, las policiales, un fenómeno que había sido relevado por Aruguete et al. (2018) y que fue reconocido por los periodistas de ambos canales en las entrevistas. Es notable aquí la predominancia de los reportes oficiales y la comunicación con actores de las fuerzas de seguridad:

\footnotetext{
La principal fuente, en general, aunque es difícil el contacto, es la policía. La policía te envía todos los días un parte diario, constantemente, de todo lo que pasó la noche anterior y durante la mañana. La segunda fuente que se consulta más para corroborar y chequear es el Ministerio Público Fiscal. Ya sea la prensa o ya sean jueces, los que menos contacto se tiene, o fiscales, sobre todo fiscales, ayudantes de fiscales o prosecretarios de fiscalía (productor de Canal 12). ${ }^{31}$

Cada cronista, camarógrafo, conductores tienen su contacto con la policía. Por ahí no te lo pasan oficialmente (productora de Canal 12). ${ }^{32}$
}

Otra periodista del mismo canal lo sintetizaba también cuando decía: "Llego a las seis de la mañana y lo primero que hago es hablar con la policía". ${ }^{33}$ En Canal 10 se

\footnotetext{
30 Entrevista personal, realizada el 11 de diciembre de 2017, Ciudad de Córdoba

31 Entrevista personal, realizada el 13 de marzo de 2018, Ciudad de Córdoba.

32 Entrevista personal, realizada el 12 de diciembre de 2017, Ciudad de Córdoba

${ }^{33}$ Entrevista personal, realizada el 13 de marzo de 2018, Ciudad de Córdoba.
} 
Laura Rosenberg, Juan Martín Zanotti

Lo impactante y lo local: criterios de noticiabilidad y fuentes de información predominantes en la producción de noticias de delito en dos canales abiertos de Córdoba

repite esta tendencia, aunque surgieron más reparos respecto a esta fuente. Como se planteó anteriormente, los cambios en la dirección del canal (y el multimedio universitario) hacia 2016 impactaron en el tratamiento de la información proveniente de fuentes policiales:

Yo llamo a la policía, a "prensa de policía", que es un poco engañoso "prensa de policía". Llamo por rutina, porque ya se hace una rutina. ¿Prensa de policía qué informa? Te puede informar sobre un accidente, te puede informar sobre un incendio... No te va a informar sobre un hecho negativo para ellos, te puede informar sobre un hecho positivo [para ellos]: "Entraron a robar, pero los detuvimos y secuestramos todo lo robado" (productora de Canal 10). ${ }^{34}$

En cuanto a esto, resulta clave recuperar lo elaborado por Tuchman (1983, p. 16) sobre la noticia como "aliada de las instituciones legitimadas", en la medida en que es recogida y diseminada por profesionales que trabajan en organizaciones, lo que la vuelve un "producto de los informadores que actúan dentro de procesos institucionales y de conformidad con prácticas institucionales. Según la autora, esto consolida el rol de los medios como reproductores del statu quo, cuestión que también ha sido analizada por Sigal (1973) y Gans (2004), quienes señalaron el rol preponderante que ocupan las fuentes oficiales en la definición del enfoque de las noticias. Esta particularidad lleva a que las noticias elaboradas por los diferentes canales presenten un encuadre similar, perdiéndose de vista la diferenciación entre las líneas editoriales que, a priori, se presentan contrapuestas (considerando la estructura de propiedad de ambos medios y el sello editorial que cada empresa busca instalar en sus producciones).

A lo anterior hay que agregarle una notoria profesionalización de las fuentes policiales, reflejada en la propia mención que los periodistas hacen de ellas en términos como "prensa de policiales", y al formato de su información como "gacetillas". Este tipo de estrategias desarrolladas por las fuentes para establecer contacto con los medios demuestra el rol activo que desempeñan en la elaboración de los productos noticiosos (Lemieux, 2000). El contacto directo con las fuentes policiales se establece cotidianamente vía redes sociales -específicamente WhatsApp- en forma particular con algunos periodistas o bien con un "parte" diario dirigido a los diferentes medios:

\footnotetext{
Antes, los partes policiales eran bastante escuetos y no te daban mucha información. Salvo la relación del tipo, en el caso de la cronista que hacía policiales tenía los teléfonos y entonces chequeaba directamente con el comisario, hablaba, era más directa la cosa. Pero ya hará unos dos meses que están utilizando el WhatsApp. Continuamente vamos recibiendo, a cualquier hora, cosas que ellos... Este es un parte [lee un mensaje en la pantalla de su celular]: "Detenido y con secuestro" y te tiran el lugar, la hora, los datos y te mandan fotos. Si hay allanamientos, te mandan fotos [...] (director de noticias de Canal 10). ${ }^{35}$
}

${ }^{34}$ Entrevista personal, realizada el 11 de diciembre de 2017, Ciudad de Córdoba.

35 Entrevista personal, realizada el 11 de diciembre de 2017, Ciudad de Córdoba. 
En relación con el trabajo con otras fuentes de información en el proceso de elaboración de las noticias sobre delito, se corroboró una mayor ponderación de las fuentes judiciales, en lo que sería un segundo grupo en importancia y a quienes se les otorga mayor crédito. En tercer lugar, le siguen las fuentes no institucionales vinculadas con víctimas, protagonistas y testigos de los hechos delictivos. De este último grupo emergió la figura de los "dateros" en el testimonio de una cronista de Canal 10, quien reafirma el rol activo de las fuentes informativas: "Tengo dateros también, dateros callejeros, urbanos [...] cuando hay algo, ellos mismos te llaman o te mandan mensajito, mandan foto [...] Es gente que pasa la noche en la calle, taxistas, policías, guardias de seguridad". ${ }^{36}$

Este último grupo se emparenta con la audiencia de los medios, que, en ambos canales, opera también -de modo marginal, aunque en un movimiento creciente- como productores de información sobre delito. En este rol que asume, la audiencia contribuye a ejercer un control sobre el desempeño de la institución policial y permite cotejar la información que las fuentes policiales ofrecen u omiten comunicar:

\begin{abstract}
En realidad, de los hechos más graves vinculados con cuestiones policiales, hoy por hoy, con el tema de los medios, te enterás vos porque la gente te llama, manda mensajes a la web. Entonces, vos ya creás un contacto. Te lo mandan por Facebook, por Twitter. Te mandan fotos, te mandan hasta los videos. Nosotros usamos un montón de videos [...] Después, la policía te lo termina confirmando cuando no puede ocultarlo más. Sobre todo, aquello que tiene que ver con temas que los vinculan más a ellos, de la inoperancia (productora de Canal 12). ${ }^{37}$

Con eldoce.tv la gente empezó a mandar fotos de robo, protestas e inseguridad. Y, hoy por hoy, con Instagram, sobre todo Facebook, más la página web, los comentarios ayudan mucho a saber en qué barrios hay más delitos [...] Hay mucho material que te manda la gente vía WhatsApp y todas las famosas redes. Vos podés arrancar con un video que mandó la gente o con un crudo que tuviste a último momento (editor de Canal 12). ${ }^{38}$
\end{abstract}

Acorde a lo desarrollado en un estudio de Calzado, Lio y Gómez (2019), se advierten en la actualidad modificaciones en la relación entre el periodismo y las fuentes policiales y las judiciales, que se plasman en lo que las autoras denominan como "un corrimiento relativo de las fuentes" (p. 220). Ello sucede cuando se produce un aumento de la imagen negativa de las fuentes oficiales, dando como resultado el recurso a otro tipo de fuentes que generan y acercan contenido a los medios tradicionales desde diversas plataformas digitales. En los casos que aquí nos ocupan, tal como expuso un editor de Canal 12 en la última cita, Canal 10 también cuenta con un portal de noti-

${ }^{36}$ Entrevista personal, realizada el 11 de diciembre de 2017, Ciudad de Córdoba.

37 Entrevista personal, realizada el 12 de diciembre de 2017, Ciudad de Córdoba.

38 Entrevista personal, realizada el 13 de marzo de 2018, Ciudad de Córdoba. 
Laura Rosenberg, Juan Martín Zanotti

Lo impactante y lo local: criterios de noticiabilidad y fuentes de información predominantes en la producción de noticias de delito en dos canales abiertos de Córdoba

cias: Cba24n.com. ${ }^{39} \mathrm{Si}$ bien este cuenta con menor interacción respecto a eldoce.tv, funciona más como un blog de participación abierta para los televidentes y se nutre de mensajes que llegan al multimedio universitario (tanto a la radio como a las señales televisivas), según planteó una productora de Canal 10: “Las redes sociales son re importantes ahora, porque seguramente va a haber una persona con información, estas [son] fuentes espontáneas". ${ }^{40}$

Si el vínculo con las fuentes policiales tenía un lugar protagónico en la organización de las rutinas cotidianas del noticiero -al constituirse en el primer contacto que los periodistas establecen diariamente para acceder a información sobre hechos delictivos-, el intercambio con fuentes no institucionales -también denominadas por la entrevistada como "fuentes espontáneas"- resulta uno de los insumos principales del cual se valen los periodistas para asignar una mayor cobertura a determinadas noticias y elaborar informes especiales que permitan diferenciar la propia cobertura sobre un hecho de la realizada por otros noticieros.

No obstante, si bien existen ciertos matices que han sido expuestos anteriormente, en relación con la percepción que se tiene sobre la fuente policial en un canal y en otro, el análisis realizado nos lleva a considerar que esta fuente institucional ocupa un rol predominante en la configuración de las noticias sobre delito en ambas señales. Se trata de un aspecto que estos noticieros comparten con los propios de otras señales, lo cual puede explicar, a su vez, que el género de estas noticias haya tendido a ser redefinido como "policial", marcando la dominancia de estas fuentes a la hora de caracterizar el delito.

\section{“Comodoro Py está en Buenos Aires": La agenda particular en torno a delitos de corrupción}

Una temática que concentró atención y que contó con extensas coberturas de los dos canales en los últimos años tuvo que ver con los juicios contra exfuncionarios de los gobiernos kirchneristas, un tópico que marcó una agenda específica, motivo por el cual se analiza en esta instancia a partir también de diferencias significativas identificadas en los tratamientos en los dos medios estudiados. La mayor distancia aparece aquí en las maneras en que en el último tiempo se han cubierto estos episodios, los cuales aluden a delitos de corrupción en el ámbito nacional. En este aspecto, se produce un corrimiento del enfoque local en el tratamiento sobre el delito y adquiere un

\footnotetext{
39 Sitio web que en el año 2015 llegó a posicionarse como el cuarto más consultado detrás de La Voz del Interior, Cadena 3 y Día a día, con un tiempo promedio de permanencia alto y poco frecuente, que en las distintas mediciones se mantuvo alrededor de los 14 minutos.

${ }^{40}$ Entrevista personal, realizada el 11 de diciembre de 2017, Ciudad de Córdoba.
} 
primer plano la noticia que llega desde Buenos Aires. Al respecto, dos entrevistados de Canal 12 comentaban:

\begin{abstract}
Cuando vienen cosas contadas de Buenos Aires, lo de TN es lo que más cortan acá. Es muy poco probable que vos lo vuelvas a editar porque eso ya viene enlatado. Le podés agregar cosas, pero por lo general bajás el informe completo de El Trece (editor de Canal 12). ${ }^{4}$ Qué sé yo, la Justicia, Comodoro Py está en Buenos Aires, es un tema nacional. Entonces ¿qué hacemos? Tomamos, lo recibimos y, en base a la información, lo ponemos. No tenemos la posibilidad de tener un cronista que pueda relatar cómo fue la llegada de Boudou a Tribunales (conductor de Canal 12). ${ }^{42}$
\end{abstract}

Resulta notable que aquí el ámbito de la justicia -incluso en fueros federales- se presenta como un tema relativo a la capital del país, que impacta localmente, aunque de manera indirecta. Ello explica en parte que el tratamiento del delito se fragmente en distintas secciones dentro de los noticieros, primando los delitos contra la propiedad privada y contra la vida en las coberturas de primera mano realizadas por cronistas especializados en policiales, y encuadrando la corrupción como asunto nacional a cargo de especialistas en el tratamiento de "judiciales".

Asimismo, esta diferenciación entre asuntos nacionales y locales se adopta para no intervenir las notas o informes producidos dentro de la misma empresa, pero que sí contempla la editorialización, principalmente de parte de los conductores de los noticieros locales. Es interesante marcar también cómo, más allá de la puesta al aire de los materiales de TN o de Canal 13, se pone por momentos en cuestión esta identificación en testimonios donde se intenta atenuar el alineamiento ideológico con Clarín, en la medida en que el peso de la pertenencia al grupo no sería comparable a la puesta de los noticieros porteños:

Lo que pasa es que el Grupo Clarín es Grupo Clarín en Buenos Aires. En Córdoba y en otras provincias, el Grupo Clarín es solo para identidad, apropiación y demás, pero por una cuestión de bajada de línea no (productor de Canal 12). ${ }^{43}$

A diferencia de lo que acontece con Canal 12 a partir de las distintas derivaciones de la confrontación pública entre Clarín y el Gobierno de la expresidenta Cristina Fernández de Kirchner -que quizás no debe analizarse como una bajada de línea directa, pero sí como una marco contextual para leer sus coberturas-, en Canal 10 se recuperaron coberturas de la Televisión Pública Argentina, se les dio un tratamiento más breve -y de menos notas- y se produjeron editoriales con menos calificativos en torno a los casos que involucraron acontecimientos judiciales vinculados con dicha administración, tanto respecto a los protagonistas como a la valoración del proceso

${ }^{41}$ Entrevista personal, realizada el 13 de marzo de 2018, Ciudad de Córdoba.

${ }^{42}$ Entrevista personal, realizada el 12 de diciembre de 2017, Ciudad de Córdoba.

${ }^{43}$ Entrevista personal, realizada el 13 de marzo de 2018, Ciudad de Córdoba. 
Laura Rosenberg, Juan Martín Zanotti

Lo impactante y lo local: criterios de noticiabilidad y fuentes de información predominantes en la producción de noticias de delito en dos canales abiertos de Córdoba

político implicado. Este aspecto también puede atribuírsele a cierta afinidad política de la conducción de la universidad y de su multimedio con el kirchnerismo - un actor que favoreció el crecimiento de las emisoras estatales (Zanotti, 2018)- hasta 2015, y más allá del cambio de gestión que introdujo otra impronta al año siguiente, se mantiene en una parte de los periodistas y de la programación.

\section{Consideraciones finales: las miradas del delito}

Con base en lo desarrollado, se resaltan aquí matices sobre las noticias de delito en los canales observados, que guardan vinculación con lo mencionado inicialmente acerca de la condición de Canal 12 de medio privado perteneciente al Grupo Clarín y de Canal 10 como un canal estatal con identidad universitaria. En una primera instancia, podría afirmarse que se distinguen menos de lo que podría imaginarse si nos apoyamos en determinados estándares para los medios estatales, presentes en las ideas referidas sobre el rol diferencial que, en términos generales, les cabría, pero también en función de la temática específica, de acuerdo con la bibliografía especializada.

En relación con las rutinas productivas, cabe destacar que luego de trabajar la cobertura informativa, se observa que tanto Canal 10 como Canal 12 plantean particularidades en los modos de concebir las ediciones del mediodía y de la noche también en temas de delito. Mientras que en la edición diurna el formato es más clásico, en la edición central enfatizan la posibilidad de agregar elementos narrativos, introducir breaking news o producir móviles con otro impacto noticioso, principalmente en Canal 12, que pareciera contar con más recursos para hacerlo. Como ha sido analizado, el factor tiempo juega aquí un papel importante, y en la medida en que la edición de la noche recupera parte de lo producido, cuenta por lo general con una mayor ventana horaria para trabajar las notas antes de la salida al aire.

La voluntad expresada en los testimonios de dar mejor tratamiento a las notas policiales o de delitos con víctimas es común a ambos medios y tiene que ver con la manera en que se evalúa el rendimiento de estas noticias, las cuales, de volverse casos resonantes, concentran la atención de la audiencia y reditúan a los informativos, a lo que se le suma lo referido sobre la cuestión geográfica y la preferencia casi exclusiva por los acontecimientos que tienen lugar en Córdoba. Para estos tratamientos existe también paridad en la preferencia por la utilización de la fuente policial como de primer orden, aunque en el canal universitario esta aparece también como una fuente criticada o puesta en cuestión y se la califica como parte interesada.

No obstante, el trabajo realizado permitió identificar puntos de contacto en el tratamiento de noticias sobre delito con base en las fuentes consultadas y al modo en que estas intervienen en el encuadre de los hechos delictivos presentes en la agenda de ambos medios. En este sentido, la interacción entre periodistas y fuentes cobra relevancia 
a la hora de entender la identificación de los criterios de noticiabilidad de esta clase de acontecimientos.

Entre estos criterios, tal como se desprende de las entrevistas realizadas, el componente local y la fatalidad resultaron aspectos distintivos. En las rutinas productivas de estas noticias, en ambos canales se destacó en primer lugar el dinamismo del intercambio cotidiano con la fuente policial. La profesionalización de los canales de comunicación con los medios informativos permitió a la institución policial establecer sus propias reglas a la hora de determinar lo que es noticiable en términos de delito. El rol de otras fuentes, como las judiciales, los "dateros urbanos" y la propia audiencia a través de las redes de los medios informativos, aportan también en esa dirección, en la cual la noticia policial resulta dominante a la hora de pensar el delito.

\section{Referencias}

Altheide, D. (1984). Creating Reality: How TV News distorts Events. Beverly Hills: Sage. Aruguete, N., y Amadeo, B. (2012). Encuadrando el delito: pánico moral en los periódicos argentinos. América Latina Hoy, 62, 177-196.

Aruguete, N., Koziner, N., Raimondo, N. y Zunino, E. (2018). Matriz para el estudio de noticias televisivas sobre delito, violencia e inseguridad: una articulación teóricometodológica. Revista Austral Comunicación, 7(2), 229-250.

Ayos, E. y Fiuza, P. (2018). (Re)definiendo la cuestión securitaria: tensiones y aperturas en las problematizaciones en torno a una "seguridad democrática" en el período 2000-2015. Delito y Sociedad, (45), 57-86.

Becerra, M. (2015). De la concentración a la convergencia. Políticas de medios en Argentina y América Latina. Buenos Aires: Paidós.

Becerra, M. y Mastrini, G. (Eds). (2017). Medios en guerra. Balance, crítica y desguace de las políticas de comunicación 2003-2016. Buenos Aires: Biblos.

Berkowitz, D. (2009). Reporters and their sources. En Wahl-Jorgensen, K. y Hanitzsch, T. (Eds), The Handbook of Journalism Studies (pp. 102-115). Nueva York: Routledge.

Bucci, E, Chiaretti, M y Fiorini, A. M. (2012). Indicadores de calidad de las emisoras públicas: evaluación contemporánea. Serie Debates CI: comunicación e información, 10, Brasilia: UNESCO. Obtenido de http://unesdoc.unesco.org/ images/0021/002166/216616por.pdf.

Calzado, M., Lio, V. y Gómez, Y. (2019). Noticias policiales y nuevos modos de narrar la "inseguridad" en la televisión argentina de aire. Ámbitos. Revista internacional de comunicación, (44), 217-243.

De Charras, D. (Comp.). (2016). Implementación del sistema de indicadores de calidad de emisoras públicas para la evaluación de la Televisión Pública Argentina. Buenos Aires: Facultad de Ciencias Sociales, Universidad de Buenos Aires. Obtenido 
Laura Rosenberg, Juan Martín Zanotti

Lo impactante y lo local: criterios de noticiabilidad y fuentes de información predominantes en la producción de noticias de delito en dos canales abiertos de Córdoba

de http://comunicacion.sociales.uba.ar/wp-content/uploads/sites/16/2015/12/ Informe-calidad-tv-p\%C3\%BAblica.pdf.

Defensoría del Público de Servicios de Comunicación Audiovisual. (2016). Monitoreo de noticieros de la TV de aire de Córdoba. Informe Anual de 2015. Obtenido de http://defensadelpublico.gob.ar/wp-content/uploads/2017/04/Informe-AnualC\%C3\%B3rdoba-2015.pdf.

Entman, R. (1993). Framing: Toward a clarification of a fractured paradigm. Journal of Communication, 43(3), 51-58.

Epstein, E. (2000). News from Nowhere: Television and the News. Chicago: I. R. Dee. Fishman, M. (1988). Manufacturing the News. Austin: University of Texas Press.

Focas, B. y Kessler, G. (2015). Inseguridad y opinión pública: debates y líneas de investigación sobre el impacto de los medios. Revista Mexicana de Opinión Pública, (19), 41-59.

Foucault, M. (1999). Vigilar y Castigar. México: Siglo XXI.

Gans, H. (2004). Deciding What's News. Chicago: Northwestern University Press.

Golding, P. y Elliott, P. (1979). Making the News. Londres: Longman.

Hallin, D. C. y Mancini, P. (2007). Sistemas mediáticos comparados. Tres modelos de relación entre los medios de comunicación y la política. Barcelona: Hacer.

Kessler, G. (2009). El sentimiento de inseguridad. Sociología del temor al delito. Buenos Aires: Siglo XXI.

Kessler, G. y Focas, B. (2014). ¿Responsables del temor? Medios y sentimiento de inseguridad en América Latina. Nueva Sociedad, (249), 137-148.

Landi, O. (1993). Devórame otra vez. Qué hizo la televisión con la gente, qué hace la gente con la televisión. Buenos Aires: Planeta.

Lemieux, C. (2000). Mauvaise presse. París: Métailié.

Lorenc Valcarce, F. (2005). El trabajo periodístico y los modos de producción de la noticia: El tratamiento de la inseguridad en la prensa argentina. En Revista Question, 1(7). Obtenido de https://perio.unlp.edu.ar/ojs/index.php/question/ article/view/108.

Martín Barbero, J. (2002). La educación desde la comunicación. Bogotá: Norma.

Mata, M. C., Morales, S. y Martinez Luque, S. (2016). Monitoreo de noticieros de la televisión de aire de la ciudad de Córdoba. Informe Anual 2014. Centro de Estudios Avanzados, Universidad Nacional de Córdoba. Obtenido de https:// rdu.unc.edu.ar/bitstream/handle/11086/4369/Documento\%2010\%20corregido. pdf? sequence $=1 \&$ isAllowed $=\mathrm{y}$.

Pelitti, P., Mársico, V. y Casazza Herrera, M. (2011). Los noticieros en la televisión actual. Question, 1(20). Obtenido de https://perio.unlp.edu.ar/ojs/index.php/question/ article/view/694. 
Rodrigo Alsina, M. (1993). La construcción de la noticia. Barcelona: Paidós.

Schlesinger, P. (1987). Putting "reality" together: BBC News. Londres: Methuen.

Scolari, C. (2008). This is the end. Las interminables discusiones sobre el fin de la televisión. La trama de la comunicación, (13), 13-25. Obtenido de https://latrama. fcpolit.unr.edu.ar/index.php/trama/article/view/69.

Sigal, L. (1973). Reporters and officials. Lexington: D.C. Heath.

Silverstone, R. (2004). ¿Por qué estudiar los medios? Buenos Aires: Amorrortu.

Sistema de Información Cultural de la Argentina (SINCA). (2017). Encuesta Nacional de Consumos Culturales. Buenos Aires: Ministerio de Cultura de la Nación. Obtenido de https://www.sinca.gob.ar/VerDocumento.aspx?IdCategoria=10

Shoemaker, P. y Reese, S. (2013). Mediating the message. Nueva York: Routledge Tuchman, G. (1983). La producción de la noticia. Barcelona: Gustavo Gili.

Tunstall, J. (1978). Journalists at Work. Beverly Hills: SAGE.

Zanotti, J. M. (2018). Medios públicos locales en reconversión. Experiencias de gestión $y$ políticas de contenidos en los Servicios de Radio y Televisión de la Universidad Nacional de Córdoba (2007-2016). (Tesis de maestría). Universidad Nacional de Córdoba. 